\title{
Chapter 11. Language Contact and Change in Melanesia
}

\section{Tom Dutton}

This paper surveys the kinds of contact-induced language change that have so far been observed in the languages of Melanesia, linguistically one of the most diverse areas of the world, if not the most diverse. It then draws on this survey to draw attention to the problems that these pose for the classification and reconstruction of the history of Melanesian languages. In some ways Melanesia is typical of the rest of the Austronesian world, but in other ways it is not.

\section{Introduction}

The topic of language contact and change in Melanesia is a vast one, and one that I cannot possibly do justice to in detail in the space available here. My aim will therefore be merely to give an overview of the types of contact-induced change that have so far been observed in that part of the Pacific that is popularly known as Melanesia (Map 1), with a view to drawing attention to certain problems that these pose for the classification and reconstruction of the history of Melanesian languages. In some ways Melanesia is typical of the rest of the Austronesian world but in other ways it is not.

Let us begin with the, now somewhat well worn, observation that Melanesia is one of the most diverse linguistic areas in the world, if not the most diverse. Here, scattered across New Guinea, the Solomon Islands, Vanuatu, New Caledonia, the Loyalty Islands and Fiji are to be found over one thousand languages, ${ }^{1}$ or approximately one-quarter of those spoken in the world today. ${ }^{2}$

Languages in this area are usually classified into two major types: Austronesian (An) and Non-Austronesian or Papuan (NAn), the latter being a general cover term for all those languages that are not An in origin without necessarily implying genetic relationship. For the most part speakers of An languages occupy the smaller islands and coastal areas of the larger islands. These languages are most closely related genetically to the languages of Polynesia and Micronesia and form with them the Oceanic (Oc) subgroup of An languages (see Pawley and Ross, this volume). Approximately 400 of the Oceanic languages are spoken in Melanesia. They belong to different first order subgroups of Oc although not everyone agrees on just what these subgroups are. Thirteen of them are Polynesian in origin and are known as the Polynesian Outliers. ${ }^{3}$ 


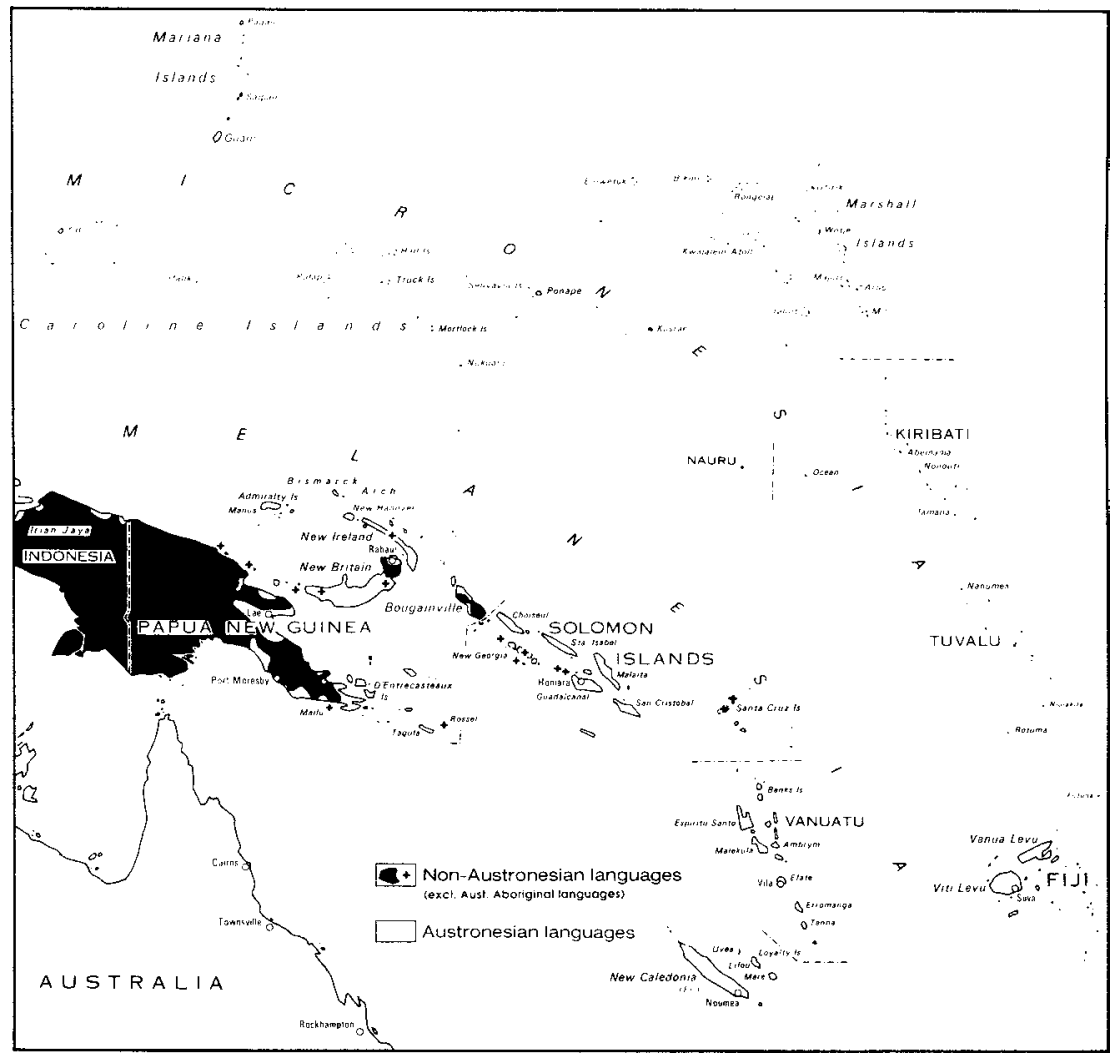

Map 1: The distribution of language types in Melanesia.

NAn languages, on the other hand, are genetically unrelated to An languages. ${ }^{4}$ They vary widely amongst themselves and do not belong to one large family like the An languages do, although some 75 per cent or so of them are thought to be distantly related to one another and to form a super-family called the Trans-New Guinea Phylum. Even so, no such relationship has yet been firmly demonstrated and the best that linguists are prepared to accept is that there are many families (about 60) which look as if they could group together in a large number of stocks and phyla. Speakers of these languages occupy the area not occupied by speakers of An languages, which for the most part is the interior of some of the larger western Melanesian islands. They are especially concentrated on the mainland of New Guinea. Because of the distributions and internal relationships of An and NAn languages it is thought that NAn languages are the older and that the An languages are intrusive. It is further believed (on the basis of both linguistic and archaeological evidence) that the Austronesian settlement of Melanesia was by descendants of the speakers of a single ancestral language, Proto-Oceanic, who arrived in the area three to four millennia ago. 
Given a situation where so many languages are concentrated in such a small area it comes as no surprise to find that speakers of these languages are, and have been, in frequent contact with each other. ${ }^{5}$ As a result the languages undergo, and have undergone, what linguists colloquially call "influence" from each other. Strictly speaking, however, languages do not influence each other. They cannot, because languages only exist as entities when spoken or written down. It is speakers who transfer the aspects of one on to another when they make choices about what to say or write in particular circumstances. But for this to happen the speakers must know some or all of the other language. In linguistic terms there must be some level of bi- or multilingualism in communities in contact before the languages used in those communities can come into contact and influence each other.

The effects of language contact are many and varied and can be quite dramatic. The main possibilities include:

a. one group giving up its language in favour of another. In linguistic circles this is called language shift. Language shifting is sensitive to social conditions and, although it is not yet a settled issue, cultural pressure in one form or another is generally regarded as the important shift-motivating factor. Some of the most common factors in this context include prestige, cultural superiority, militaristic dominance and demographic superiority. ${ }^{6}$ If the dominant group is large it is likely that the shifting group will eventually learn the target language. However, if the relationship changes (as for example, if the dominant group is reduced in size for some reason or loses power) or if the shifting group is able to survive as a homogeneous or close-knit subgroup within the target language community (as happens with some ethnic minorities in Australia), the shifting group's form of the language may become established as the norm. In this case the norm will show the effects of borrowing, often called language shift interference or substratum influence - the subordinate speakers have influenced the language in the direction of their original language.

b. two or more languages existing side by side without any interference. This can only happen in very special circumstances, when, for example, neither group utters a word of the other's language even though the two groups may come together for certain purposes (such as trading), or when speakers of one language learn to understand the other but never use it. Speakers in this latter situation are said to be passively bilingual (that is understand a language but not speak it) or to be dual lingual (as, for example, when two people speak different languages and converse by doing so, each being passively bilingual in the other's language).

c. borrowing of elements of one language into another. This is the most common type of influence one language has on another and may involve 
all aspects of a language, from sounds to grammar and vocabulary. Theoretically any feature of a language may be borrowed, although this has only recently been acknowledged. For a long time it was assumed, for example, that grammatical elements would only be borrowed between dialects (or variants of a language) or very similarly structured languages. Nevertheless, in practice we find that given the right social conditions any aspect of a language can be borrowed. For this to happen, however, special social circumstances have to be operating. In general, social factors are the most important determinants for borrowing, although linguistic factors such as the similarity of the structure of the two languages (or what linguists call typological distance between them) are not unimportant. ${ }^{7}$ Although there is a range of terms used by linguists to talk about borrowing there are three well-known if somewhat old fashioned terms which cover most cases. These are what Bloomfield (1933:444-495), the so-called Father of American Linguistics, called "dialect borrowing", "cultural borrowing" and "intimate borrowing", although in Melanesia it is often difficult to distinguish between the results of partial language shift, heavy cultural borrowing and intimate borrowing.

i. Dialect borrowing. As the name suggests this is the kind of borrowing that occurs between dialects or varieties of a language. It is also applied to that between typologically very similar languages. In this kind of borrowing changes introduced are generally very minute and result mainly from groups of speakers favouring one way of saying something over another, rather than from the adoption of wholly new forms of vocabulary or grammar. Dialect borrowing is perhaps the most difficult problem that linguists have to deal with in trying to classify languages and in reconstructing their histories, because it often goes undetected. ${ }^{8}$

ii. Cultural borrowing. This is the term used to describe the kind of borrowing that occurs when two or more groups of people come into contact and learn words for things they do not have and are interested in obtaining from each other. This kind of borrowing implies casual contact and is most likely to occur where there are cultural differences. It is ordinarily mutual (as the rather crude definition above suggests), but it does not have to be. It is one-sided only to the extent that one group has more to give than the other. Because it is associated with casual contact the borrowing usually only involves vocabulary. This kind of borrowing is also usually very easy to identify because it is restricted to certain kinds of items and is usually phonologically irregular in some way. Finally the borrowing process does not affect the borrowing language's sound system. Consider, for example, how little the pronunciation of British citizens in India was affected by the adoption of many words of Indian origin. 
iii. Intimate borrowing. This type of borrowing occurs when a group of speakers attempts to learn the language of its contacts. As a result it implies some degree of second language learning, some kind of bilingualism (or multilingualism) although it does not necessarily imply language shift. ${ }^{9}$ That may be an unintended result, however. Thus, as will be pointed out later, where language differences serve group identity (or emblematic) functions, as in Melanesia, a group of speakers may come to regard another language as part of its "pool of linguistic resources" (Grace 1981:264) for various social purposes. That is, speakers keep their mother tongue for group identity purposes but become so familiar with the second language that they may transfer the features of that language to their mother tongue. As a result the structure and vocabulary of their mother tongue may be influenced by that of the second language. The learning of the second (or third or however many) language normally takes place as a result of some "felt need" or perceived social advantage on the part of the learners. Borrowing or linguistic influence in this case implies close or intense contact. Often the first indication that intimate borrowing has taken place is that the language proves difficult to classify or that the original status of the language as An or NAn is not immediately clear. In Melanesia a number of such difficult-to-classify languages have been called "mixed languages" (Capell 1976), although the term is a controversial one and not accepted by everyone.

d. the development of a third language not identical to either. This is the case again when special social conditions prevail, such as, for example, when communities come into contact to trade ${ }^{10}$ or when one group of people is imprisoned by or forced to work for another (as happened in the Pacific last century for example). In these situations there is a need to communicate before there is time to learn one or the other of the languages spoken by the contacting groups or when there are other barriers to doing so. Such languages are usually restricted in vocabulary and simplified in structure compared with the languages in contact. They are specific purpose languages and are not spoken natively. They are called pidgin languages. ${ }^{11}$

\section{Language Contact and Change in Melanesia}

\section{Language Shift and Obsolescence}

Although we do not have records to show how often this occurred in the past - Melanesian societies kept no written records and were apparently not sufficiently concerned about the demise of languages to keep oral traditions about them for any significant length of time - there were sufficient numbers of cases of languages in the last stages of obsolescence at the time of European contact for us to presume that it was a reasonably regularly occurring event 
prehistorically. It would appear that the conditions favouring language shift in Melanesia are similar to those noted elsewhere - the absorption of remnants of larger groups seeking refuge from intertribal warfare and natural disasters (such as droughts, floods and epidemics) or small numbers of people pursuing perceived economic or cultural advantages. In any case, both An and NAn languages were involved (Dutton and Mühlhäusler 1991).

\section{No Influence}

It is hard to find cases in this category because the potentially instructive ones either have not been fully described or do not live up to expectations on further investigation. For example, even though we have reported cases of dual lingualism involving An and NAn language speakers, in the best described one the An languages involved, Banoni and Piva, do show low levels of cultural borrowing from neighbouring Papuan languages (Lincoln 1976:97-99).

\section{Borrowing}

\section{Dialect Borrowing}

By its very nature this kind of borrowing is difficult to identify. It usually shows up, however, in detailed comparative work as inconsistent sound correspondences and/or as dialect chaining. Thus, for example, in Papuan Tip (PT) languages in the Milne Bay Province of Papua New Guinea some reflexes of PPT * $b$, * $d$ and * $g$ occur voiced instead of being voiceless as expected (Ross 1988:198-202). These voiced reflexes are evidently the result of dialect borrowing from neighbouring languages.

Chaining occurs when a string of communities share sets of features with each other in an overlapping fashion so that community A shares some features with community B, which in turn shares some features with community C, and so on. The phenomenon was first described by Wurm and Laycock (1961-62) in discussing problems of classification in Papua New Guinea. Its existence introduces a certain arbitrariness in the definition of "language" and "dialect" in Melanesia and explains why linguists differ about the number of languages actually spoken therein. In his detailed study of the An languages of western Melanesia, Ross (1988:8) distinguishes between "chains" and "networks", the former being used for "communalects that are typically spread along a coastline, each related most closely to its neighbour on either side", and the latter for "communalects scattered over a land area or an archipelago, typically having neighbours on more than two sides and often sharing different innovations with several of these".

Dialect borrowing therefore poses problems for the traditional family tree model of language diversification. To cope with it linguists are forced to adopt 
models that allow for diversification through contact-induced change, as Ross (1988) did in his exemplary study.

\section{Cultural Borrowing}

This is the most common kind of borrowing noted in Melanesia - at least it is the one most easily identified and most often reported. It is particularly common in NAn languages in contact with An ones and in Melanesian An languages in contact with Polynesian Outlier ones. In both these cases it is particular cultural items that seaboard or incoming Austronesians have that other resident communities seek and hence borrow vocabulary for. Thus, for example, the NAn Koita around Port Moresby have borrowed sailing and sea terminology (including terms for marine life) from their Austronesian neighbours, the Motu (Dutton 1994). The An languages near Polynesian Outlier languages have done very much the same thing, borrowing not only Polynesian terms for the sea and sailing but also words associated with kava drinking and artefacts made from coconut fronds (Clark 1994). This picture is repeated many times in the literature and is part of the folk wisdom of Oceanic linguists. ${ }^{12}$ By definition this kind of borrowing is one sided or at most unequal, although it is not always quite as straightforward as this suggests. Indeed it is very sensitive to socio-cultural realities and may be bound up with intimate borrowing as well. Thus, for example, Clark (1986) describes how the Polynesian Outlier languages of Emae and Mele-Fila in Vanuatu have borrowed intimately from neighbouring An languages which in turn only show effects of cultural borrowing. ${ }^{13}$ The reasons for this are apparently demographic — the Polynesians were (and still are) much fewer in number than their Melanesian neighbours and in seeking wives and in trading they would have had to, as Clark says,

deal with Melanesian speakers more often than not, whereas Melanesian speakers, on average, would have had only a minority of Polynesian contacts. Melanesian wives, in particular, marrying into Polynesian villages, bearing and rearing children, speaking a Melanesian-influenced second-language variety, would have accomplished both the physical and the linguistic assimilation of the immigrants (Clark 1986:341).

Such cases show that, even though the principles of cultural borrowing are clear, it is not possible to predict the effects in particular cases without knowing the social conditions operating. Consequently it is often not possible to distinguish between the effects of heavy cultural borrowing and intimate borrowing.

\section{Intimate Borrowing}

It has long been known that, structurally, the An languages of the Papua New Guinea area fall into two main types, those with a basic SOV (subject - object verb) word order and those with a basic SVO word order. ${ }^{14}$ Practically all of 
the mainland An languages and those of south-eastern Papua and its associated offshore islands are of the first type while those of the second type are found mainly in New Britain and New Ireland. As well, the basic word order SOV coincides with that of most NAn languages. It has therefore been suggested that the structural difference between these two groups of An languages is to be attributed to contact with NAn languages some time in the past. Although it has not been possible to identify any particular NAn language or group of such languages to support this claim it seems highly likely that this difference was the result of intimate borrowing.

Apart from this case and a number of other well known cases of language "mixing" described briefly below (which derive from intimate borrowing between An and NAn languages), ${ }^{15}$ relatively few cases of this kind of borrowing have appeared in the literature until recently. One such case is Labu, an An language spoken near Lae, Papua New Guinea. This is a small language of 1700 speakers that is surrounded by speakers of two other An languages, Bukawa and Kela. For many years the genetic position of Labu vis-à -vis related languages in the same area has been ambiguous. Holzknecht (1994) shows, however, that Labu is a member of the Markham Family that has been heavily influenced by Bukawa and possibly also Kela (both closely related to one another and members of the North Huon Gulf Chain) in phonology, grammar and vocabulary. Although she does not say as much this case appears to be one of intimate borrowing between An languages. This is not only evident from the fact that all aspects of the structure have been influenced but also from the fact that the Labu have been socially in "more or less intense" contact with the Bukawa. Indeed, some of the early Labu "spent some time within Bukawa-speaking communities in a client (Labu)-patron (Bukawa) relationship" as refugees (Holzknecht 1994:371), and some children grew up bilingual in Labu and Bukawa. This is not regarded as a case of dialect borrowing, however, because, even though the languages are An, they are not sufficiently closely related or typologically similar to fit the definition given above.

More elaborate cases are those described briefly by Clark (1994), who discusses a complex situation obtaining amongst the Polynesian Outlier languages. He notes that none of the Polynesian languages is "pure" in the sense of having undergone no influence but the influence is scaled - it is greatest on those languages geographically closest to non-Polynesian languages and least in the most remote or isolated communities. Two languages, Mele-Fila and Emae, show unmistakable signs of intimate borrowing from non-Polynesian languages nearby. Two others, Rennellese and Fagauvea, show signs of cultural and intimate borrowing at work together. In other cases it is not clear if the evidence is indicative of intimate borrowing or the influence is a secondary effect of cultural borrowing on a large scale. The picture is further complicated by the fact that (i) at least in one case, Anuta, multiple settlements have occurred from Polynesia 
on the one island, (ii) in other cases there has been contact with neighbouring Polynesian communities that have a common settlement history. On the other hand, none of the non-Polynesian languages has undergone anything like the borrowing seen in the more affected cases of Polynesian languages. In general they have only borrowed culturally relevant vocabulary of a kind already noted above. The explanation for the observed borrowing pattern is demographic the Polynesian communities are all small even by Melanesian standards.

\section{So-called "Mixed" Languages}

These are special cases of intimate borrowing where the languages have undergone so much influence from some other language or languages that there has been considerable debate about their original status. They include Magori, Maisin and the Reef-Santa Cruz languages, and in a slightly different category, Lusi.

Magori is an An language of the southeast coast of Papua New Guinea. At the time of European contact it was only spoken in two small villages in the Bailebo River valley almost opposite Mailu Island where the principal village of the NAn Mailu (or Magi) is situated. When first recorded it was thought that Magori was part of the Mailu language, if apparently somewhat aberrant. Subsequent investigation showed, however, that it was originally an An language from which the Mailu had initially borrowed. Later, it appears that something happened to put the Magori in a position where at first contact they were living in fear of the Mailu and were learning their language. In the process they were borrowing back words that the Mailu had originally borrowed from them in a different form (Dutton 1982). This borrowing has been very heavy but so far it does not seem to have affected the grammar and phonology very much. However, Magori and remnants of three other closely related An languages, Ouma, Yoba and Bina, have become more alike as a result of mutual loaning and borrowing with other neighbouring An languages. Lexically, they now appear to be co-ordinate between eastern and western groups of An languages along the south coast of Papua (Dutton 1976, 1982).

Maisin is spoken in two areas corresponding to two dialect divisions in the Northern Province of Papua New Guinea - one in the coastal area of Collingwood Bay and one in several villages in the swamps between the mouths of the Musa and Bariji Rivers in Dyke Ackland Bay (Dutton 1971). For many years this language had been an enigma, some scholars classifying it as originally An and others as originally NAn. In 1977, however, Lynch showed fairly conclusively that although it had a vocabulary of mixed origins its grammar was basically An. It is now clear that it originally belonged to the Are-Tauopota Chain of Papuan Tip languages (Ross 1988). Its present "mixed" status arises from the fact that it was evidently in close contact with some (as yet unidentified) NAn 
language or languages in which the speakers were bilingual and as a result has been heavily influenced by it or them.

The Reefs-Santa Cruz languages spoken in the islands of the same name in the eastern Solomon Islands are similar to Maisin in that investigators have disagreed about their original status. Wurm (1978), for example, argued that they were originally NAn and Lincoln (1978) argued that they were An. This controversy has not been satisfactorily resolved to date.

Lusi is an An language spoken in the West New Britain Province of Papua New Guinea. According to Thurston (1982), Lusi is a creole language (that is, a pidgin language that has become the native language of a group of speakers) which has developed from a pidginized An language through contact with the NAn language Anêm (Thurston 1982:71). Thurston's use of the word "pidginized" is aimed at emphasizing the rapid nature of change that was involved in this transformation and the changes the language has undergone. ${ }^{16}$ It was an exaggerated position adopted to draw attention to the normally accepted view that language change is gradual. In reality it is no different from related languages in the area. While it has undergone changes not undergone by others, most probably as a result of contact with Anêm, it is not so different for it to be put in a special category.

\section{Pidgins}

So far, seven of these have been reported involving An languages in Melanesia, only five of which have been documented in any way. ${ }^{17}$ of these two had to do with the hiri trade in central Papua involving An and geographically distant NAn language speakers (Dutton 1985). Another two developed with trade between the An Mekeo and neighbouring NAn language speakers in central Papua (Jones 1985). In a slightly different but related category was a kind of "foreigner talk" used by the An Motu of the Port Moresby area to communicate with visiting foreigners. An administrative language called Police Motu which developed in Papua after European contact is thought to have developed out of this special variety of Motu (Dutton 1985).

This number of reported pidgin languages is surprisingly small, given the linguistic diversity of Melanesia and the number of trading networks in which there was contact between An and NAn languages, as well as between An and An languages including Polynesian Outlier languages. Amongst the more important reasons for this are possibly the following:

a. that where trading was between neighbouring groups, bi- or multi-lingualism took care of the problem of communication;

b. that pidgin languages have not been considered worthy of any attention by linguists until recently and have therefore gone unreported in the past. 
It is to be particularly noted that there are no examples of pidgins arising out of An-An contact. ${ }^{18}$

\section{Implications for Classification and Historical Reconstruction}

If there is one point that stands out above all others in this survey it is that there has been much more contact between the different types of languages in Melanesia than most scholars have been prepared to acknowledge in the past. As a result, we must be prepared to accept that the linguistic and archaeological prehistories of the area are that much more complicated than hitherto suspected or acknowledged.

Scholars interested in the classification and origin of An languages have long known about and been fascinated by the diversity aspect of Melanesian languages. While those languages share what Grace called "a characteristic uniformity" (or "tendency to sameness") in some respects, they also display a "remarkable diversity" in others (Grace 1968:67). However, those same scholars have often argued at cross purposes about the underlying reasons for this because they have generally failed to recognize that there is not just one kind of diversity, but several.

The first kind of diversity to be recognized is that which is referred to in the opening paragraph to this paper, notably, the sheer number of languages concentrated in a small area. Actually it is not merely the absolute number that is the interesting and significant thing, but, as Pawley (1981) points out, the number of languages per island group. Thus, when compared with Polynesia, for example, Melanesia has many languages per island group while Polynesia usually has only one. Why is this so? Pawley's answer was that Melanesian diversity was not "brought about by mechanisms of a radically different kind from those which operated in Polynesia" (Pawley 1981:273). Rather, the sequence of diversification was much the same in both areas, the only difference being that "the cycle of linguistic diversification" had more time to apply in Melanesia than in Polynesia (Pawley 1981:298). While he saw various socio-economic and political factors as important in this speciation process, Pawley did not see contact with NAn communities as a "necessary ingredient in the recipe for Melanesian linguistic diversity" (Pawley 1981:274-275). He did acknowledge, however, that the presence of such populations may have hastened the process. As he himself noted on a later occasion (Pawley 1990), this type of diversity is not much of a puzzle. It can be accounted for by the sorts of mechanisms outlined in his paper.

Two other kinds of diversity are more interesting. They have to do with variation between An languages in Melanesia. In the first kind the focus is on the way some languages differ markedly from other An languages and reconstructed proto-languages in their sound systems and grammars. The second type has to do with the distribution of cognates across languages, some languages 
having relatively few. Those that are most divergent in these senses are often referred to as "aberrant" or "problematic" (Grace 1990), and those that have changed least as "conservative" or "exemplary". Between these two are degrees of aberrancy so that languages can be ranged on a scale (although no one has actually tried to do this) from least to most aberrant (Grace 1990). The Markham River languages in Papua New Guinea, New Caledonian languages and those of south Tanna in Vanuatu in particular have reputations of being the most aberrant. Indeed, although An languages in Melanesia are classified as An, that is, as descendants of Proto-Oceanic, they vary so widely in structure and vocabulary that linguists are still debating how they should be classified internally (see Pawley and Ross, this volume).

Scholars have long puzzled over the reasons for these two kinds of diversity and have sought to explain them in varying ways. The first to do so was S.H. Ray (1926), who suggested that the present forms of An languages in Melanesia resulted when incoming An speakers from Indonesia settled in Melanesia and came into contact with resident NAn populations. Later, Capell (who was actually a student of Ray's) carried this idea forward in various publications, giving rise to what is known as the "pidginization hypothesis". Both Ray and Capell pointed to the small proportion of vocabulary in Melanesian An languages that could be related to Indonesian vocabulary. ${ }^{19}$ Capell (1943) further claimed that a study of this vocabulary shows that the languages of southeast Papua, for example, derived their particular features from having been in contact with a number of "regional" NAn languages, certain features of which could be reconstructed from that same vocabulary.

For a long time this pidginization hypothesis was rejected by later linguists as based on false assumptions and bad methodology. ${ }^{20}$ Grace (1962), in summing up the controversy, challenged supporters of it to find a Melanesian language in which the non-An elements could be attributed to a specific NAn language. Thurston (1982) took up this challenge and provides evidence from Lusi in West New Britain that he says is "capable of resolving the argument in favour of Capell and Ray" (Thurston 1982:2). His examination of both lexical and grammatical evidence leads him to conclude, as already pointed out, that Lusi is a creole language which has developed from a pidginized An language through contact with the NAn language Anêm. Thurston is so convinced by what he finds in Lusi and other languages of the same area that he believes that pidginization (in his sense) was the major factor in the diversification of Mn languages (1987, 1994).

Meanwhile, Lynch (1981) also took up the challenge implicit in Pawley's 1981 paper referred to above and argued that the many-languages -per-island-group type of diversity as found in Melanesia was not solely a reflection of different time depths and particular socio-economic and political 
conditions. He felt that contact between An and NAn languages was also an important factor. In support of his claim he appealed to the specific mixed-language-type case studies of Magori, Maisin, Lusi and Reefs-Santa Cruz that have been mentioned above.

Since then Grace, responding to more recent detailed work by a number of younger scholars including those already mentioned, has acknowledged that there is much that is left unexplained by the traditional views of language diversification and change based on the family tree model. He has called for a reassessment of "all the facts" (1985:3).

Part of the problem in the past has been, of course, that scholars have attempted to provide a unified "solution" to what has often been called "the Melanesian problem" (Grace 1968), without distinguishing between the different types of diversity described above and without attempting to find separate "solutions" for each kind. What such scholars failed to acknowledge was that there are many factors besides time depth and language contact that have been involved in producing the kinds of diversity found in Melanesia today. Attitudes to language, and what Don Laycock used to call "conscious human monkeying with language", are two such factors. Laycock describes how in one dialect of Buin, a NAn language of south Bougainville, gender distinctions in grammar are the exact reverse of those in other dialects - what is male in other dialects is female in this dialect (1982:35). Melanesians thus appear to foster linguistic diversity purposefully because they see linguistic differences as important badges of group identity. It is, as it were, a Melanesian choice to promote diversity (Laycock 1982:34).

One thing is certain, and that is that diversity must be functional in some way; otherwise, as Grace points out, it is maintained at too great a social cost why learn to be different when being the same would be less taxing? Nor can diversity be explained solely by migration, as that would require too many independent moves (Grace 1975; Thurston 1987:94ff.). At the same time, Melanesian societies have placed a high value on multilingualism. The public display of knowledge of other languages has long been noted as an important means of gaining prestige in Melanesia (Salisbury 1962; Sankoff 1977).

Another factor that needs to be taken into account in attempting to explain linguistic diversity in Melanesia is word tabooing. This is the social action of forbidding the use of a word that is associated in some way with a member of the community who has just died. It is a common feature of many Melanesian societies and leads to "unnatural" replacement of vocabulary (Simons 1982; Holzknecht 1988). 


\section{Future Research Needs}

Notwithstanding the marked improvement in knowledge of particular Melanesian languages and groups of languages in recent years, there are still many questions that have to be answered before we can say that the field of language contact and change has been adequately covered. Just how far we still have to go can perhaps be most simply illustrated by pointing out that, whereas the results of An-NAn contact figure prominently in the discussion above, those of An-An contact do so only to a much lesser degree. This can be shown by a table such as the following that displays the types of contact studies that have figured in the discussion above. In this '\#' indicates that no case has been adequately described to date and ' + ' means one or more cases have been reported:

Type (resulting from):

a) obsolescence

b) dual lingualism

c) borrowing dialect borrowing cultural borrowing intimate borrowing "mixed" language

d) pidgin language
An-An contact

\#

\#

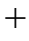

$+$

$+$

\#

\#
An-NAn contact

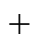

$+$

$+$

$+$

$+$

$+$

Although crude, this table is nevertheless quite instructive because it clearly shows that the types of reported cases are skewed in favour of An-NAn contact. Thus, while An-NAn contact has produced all possible results, An-An contact seems to result only in different types of borrowing. To what can this skewing be attributed? Does it merely represent poor socio-linguistic investigation and reporting, or are there other explanations? To answer these sorts of questions we need more in-depth studies of particular cases focused not only on traditional descriptive and comparative historical questions, but also on such aspects as the following that Grace $(1975,1985,1990)$ has drawn attention to:

- $\quad$ societal attitudes to language correctness and accelerated language change;

- the way sound changes are introduced and spread;

- social isolation and its effect on rate of change;

- inter- versus intra-community diversity;

- the definition of "the language of a community".

In other words we need much more detailed information than we have had hitherto. With many new scholars entering the field, better trained than in the past, there is every prospect of achieving the desired goals. 


\section{References}

Bloomfield, Leonard

1933 Language. London: Allen \& Unwin.

Bugenhagen, Robert

1994 Language change on Umboi Island. In Tom Dutton and Darrell Tryon (eds) Language contact and change in the Austronesian world, pp.43-108. Berlin: Mouton de Gruyter.

Capell, Arthur

1943 The linguistic position of south-eastern Papua. Sydney: Australasian Medical Publishing Co.

1962 Oceanic linguistics today. Current Anthropology 3:371-428.

1971 The Austronesian languages of Australian New Guinea. Current Trends in Linguistics 8:240-340.

1976 Austronesian and Papuan 'mixed' languages: general remarks. In S.A. Wurm (ed.) New Guinea area languages and language study, vol. 2: Austronesian languages, pp.527-579. Pacific Linguistics Series C No. 40.

Canberra: Department of Linguistics, Research School of Pacific Studies, The Australian National University.

Clark, Ross

1986 Linguistic convergence in central Vanuatu. In P.A. Geraghty, Lois Carrington and S.A. Wurm (eds) FOCAL II: Papers from the fourth international conference on Austronesian linguistics, pp.333-342. Pacific Linguistics Series C No. 94. Canberra: Department of Linguistics, Research School of Pacific Studies, The Australian National University.

1994 The Polynesian Outliers as a locus of language contact. In Tom Dutton and Darrell Tryon (eds) Language contact and change in the Austronesian world, pp.109-139. Berlin: Mouton de Gruyter.

Dorian, Nancy (ed.)

1989 Investigating obsolescence: studies in language contraction and death. Cambridge: Cambridge University Press.

Dutton, T.E.

1971 Languages of South-East Papua: a preliminary survey, pp.1-46. Pacific Linguistics Series A No. 28. Canberra: Department of Linguistics, Research School of Pacific Studies, The Australian National University.

1976 Magori and similar languages of South-East Papua. In S.A. Wurm (ed.) New Guinea area languages and language study, vol. 2: Austronesian languages, pp.581-631. Pacific Linguistics Series C No. 40. Canberra: Depart- 
ment of Linguistics, Research School of Pacific Studies, The Australian National University.

1978 Language and trade in central and southeast Papua. Mankind 11(3):341353.

1982 Borrowing in Austronesian and non-Austronesian languages of coastal south-east mainland Papua New Guinea. In Amran Halim, Lois Carrington and S.A. Wurm (eds) Papers from the third international conference on Austronesian linguistics, Vol 3: Accent on variety, pp.109-177. Pacific Linguistics Series C No. 76. Canberra: Department of Linguistics, Research School of Pacific Studies, The Australian National University.

1985 Police Motu: iena sivarai (its story). Port Moresby: The University of Papua New Guinea Press.

1994 Motu-Koiarian contact in Papua New Guinea. In Tom Dutton and Darrell Tryon (eds) Language contact and change in the Austronesian world, pp.181-232. Berlin: Mouton de Gruyter.

Dutton, T.E. and Malcolm Ross

1992 A note on Hees' 'Tolai-Nakanai' trade language. Language and Linguistics in Melanesia 23(2):198-204.

Dutton, Tom and Darrell Tryon (eds)

1994 Language contact and change in the Austronesian world. Berlin: Mouton de Gruyter.

Dutton, Tom and Peter Mühlhäusler

1991 Are our languages dying? Occasional papers in language and literature, 1(1):50-72. Port Moresby: The University of Papua New Guinea.

Foley, William A.

1986 The Papuan languages of New Guinea. Cambridge: Cambridge University Press.

Geraghty, P.A.

1994 Linguistic evidence for the Tongan Empire. In Tom Dutton and Darrell Tryon (eds) Language contact and change in the Austronesian world, pp.233-249. Berlin: Mouton de Gruyter.

Geraghty, P.A., Lois Carrington and S.A. Wurm (eds)

1986 FOCAL II: Papers from the fourth international conference on Austronesian linguistics. Pacific Linguistics Series C No. 94. Canberra: Department of Linguistics, Research School of Pacific Studies, The Australian National University.

Grace, George W. 
1962 Comment. Current Anthropology 3:408-410.

1968 Classification of the languages of the Pacific. In A.P. Vayda (ed.) Peoples and cultures of the Pacific, pp.63-81. New York: Natural History Press.

1975 Linguistic diversity in the Pacific: on the sources of diversity. Working Papers in Linguistics, University of Hawaii 7(3):1-7.

1981 Indirect inheritance and the aberrant Melanesian languages. In [K.J.] Jim Hollyman and Andrew Pawley (eds) Studies in Pacific languages \& cultures, in honour of Bruce Biggs, pp.255-268. Auckland: Linguistic Society of New Zealand.

1985 Oceanic subgrouping: retrospect and prospect. In Andrew Pawley and Lois Carrington (eds) Austronesian linguistics at the 15th Pacific Science Congress, pp.1-18. Pacific Linguistics Series C No. 88. Canberra: Department of Linguistics, Research School of Pacific Studies, The Australian National University.

1990 The 'aberrant' (vs. 'exemplary') Melanesian languages. In Philip Baldi (ed.) Linguistic change and reconstruction methodology [Trends in Linguistics. Studies and Monographs 45], pp.155-173. Berlin/New York: Mouton de Gruyter.

Guy, Gregory R.

1990 The sociolinguistic types of language change. Diachronica 7(1):47-67.

Halim, Amran, Lois Carrington and S.A. Wurm (eds)

1982 Papers from the third international conference on Austronesian linguistics, Vol 3: Accent on variety. Pacific Linguistics Series C No. 76. Canberra: Department of Linguistics, Research School of Pacific Studies, The Australian National University.

Harding, T.G.

1967 Voyagers of the Vitiaz Strait: a study of a New Guinea trade system. Seattle and London: University of Washington Press.

Holm, John

1988 Pidgins and creoles, 2 vols. Cambridge: Cambridge University Press.

Hollyman, [K.J.] Jim and Andrew Pawley (eds)

1981 Studies in Pacific languages \& cultures, in honour of Bruce Biggs. Auckland: Linguistic Society of New Zealand.

Holzknecht, Susanne

1988 Word taboo and its implications for language change in the Markham family of languages, Papua New Guinea. Language and Linguistics in Melanesia 18(1):43-69. 
1994 The mechanisms of language change in Labu. In Tom Dutton and Darrell Tryon (eds) Language contact and change in the Austronesian world, pp.351-376. Berlin: Mouton de Gruyter.

Jones, Alan

1985 Two Mekeo pidgins. Unpublished MS. Research School of Pacific Studies, The Australian National University.

Laycock, D.C.

1982 Linguistic diversity in Melanesia: a tentative explanation. In Rainer Carle, Martina Henschke, Peter W. Pink, Christel Rost and Karen Stadtlender (eds) GAVA': studies in Austronesian languages and cultures, dedicated to Hans Kähler, pp.31-37. Berlin: Dietrich Reimer.

Lincoln, Peter C.

1976 Banoni, Piva and Papuanization, pp.77-105. Pacific Linguistics Series A No. 45. Canberra: Department of Linguistics, Research School of Pacific Studies, The Australian National University.

1978 Reef-Santa Cruz as Austronesian. In S.A. Wurm and Lois Carrington (eds) Second international conference on Austronesian linguistics: proceedings, pp.929-967. Pacific Linguistics Series C No. 61. Canberra: Department of Linguistics, Research School of Pacific Studies, The Australian National University.

Lynch, John

1977 Notes on Maisin — an Austronesian language of the northern province of Papua New Guinea. Unpublished MS. Port Moresby: University of Papua New Guinea.

1981 Melanesian diversity and Polynesian homogeneity: the other side of the coin. Oceanic Linguistics 20:95-129.

1994 Melanesian sailors in a Polynesian sea: maritime vocabulary in Southern Vanuatu. In A. Pawley and M. Ross (eds) Austronesian terminologies: continuity and change, pp.289-300. Pacific Linguistics Series C No. 127. Canberra: Department of Linguistics, Research School of Pacific and Asian Studies, The Australian National University.

Mühlhäusler, Peter

1986 Pidgin and creole linguistics. Oxford: Blackwell.

Pawley, Andrew K.

1981 Melanesian diversity and Polynesian homogeneity: a unified explanation for language. In K.J. Hollyman and A. Pawley (eds), Studies in Pacific 
languages \& cultures, in honour of Bruce Biggs, pp.269-309. Auckland: Linguistic Society of New Zealand.

1990 A simple linguist's view of Pacific prehistory. Unpublished seminar paper, Research School of Pacific Studies, The Australian National University.

Pawley, Andrew and Lois Carrington (eds)

1985 Austronesian linguistics at the 15th Pacific Science Congress. Pacific Linguistics Series C No. 88. Canberra: Department of Linguistics, Research School of Pacific Studies, The Australian National University.

Ray, Sidney H.

1926 A comparative study of the Melanesian Island languages. Cambridge:

Cambridge University Press.

Ross, Malcolm D.

1984 Maisin: a preliminary sketch, pp.1-82. Pacific Linguistics Series A No. 69. Canberra: Department of Linguistics, Research School of Pacific Studies, The Australian National University.

1988 Proto-Oceanic and the Austronesian languages of western Melanesia. Pacific Linguistics Series C No. 98. Canberra: Department of Linguistics, Research School of Pacific Studies, The Australian National University.

1991 Refining Guy's sociolinguistic types of language change. Diachronica 8:119-129.

1994 Central Papuan terms for the maritime environment. In A. Pawley and M. Ross (eds) Austronesian terminologies: continuity and change, pp.389479. Pacific Linguistics Series C No. 127. Canberra: Department of Linguistics, Research School of Pacific and Asian Studies, The Australian National University.

Salisbury, R.F.

1962 Notes on bilingualism and linguistic change in New Guinea. Anthropological Linguistics 4(7):1-13.

Sankoff, Gillian

1977 Multilingualism in Papua New Guinea. In S.A. Wurm (ed.) New Guinea area languages and languages study, Vol. 3: Language, culture, society and the modern world, pp.265-307. Pacific Linguistics Series C No. 40. Canberra: Department of Linguistics, Research School of Pacific Studies, The Australian National University.

Simons, Gary 
1982 Word taboo and comparative Austronesian linguistics. In Amran Halim, Lois Carrington and S.A. Wurm (eds) Papers from the third international conference on Austronesian linguistics, Vol. 1: Currents in Oceanic, pp.157226. Pacific Linguistics Series C No. 74. Canberra: Department of Linguistics, Research School of Pacific Studies, The Australian National University.

Thomason, Sarah Grey and Terrence Kaufman

1988 Language contact, creolization, and genetic linguistics. Berkeley: University of California Press.

Thurston, William R.

1982 A comparative study of Anêm and Lusi. Pacific Linguistics Series B No. 83. Canberra: Department of Linguistics, Research School of Pacific Studies, The Australian National University.

1987 Processes of change in the languages of north-western New Britain. Pacific Linguistics Series B No. 99. Canberra: Department of Linguistics, Research School of Pacific Studies, The Australian National University.

1994 Renovation and innovation in the languages of north-western New Britain. In Tom Dutton and Darrell Tryon (eds) Language contact and change in the Austronesian world, pp.573-609. Berlin: Mouton de Gruyter.

Trudgill, Peter

1986 Dialects in contact. Oxford: Blackwell.

Tryon, Darrell

1994 Language contact and contact-induced language change in the Eastern Outer Islands, Solomon Islands. In Tom Dutton and Darrell Tryon (eds) Language contact and change in the Austronesian world, pp.611-648. Berlin: Mouton de Gruyter.

Valdman, Albert (ed.)

1977 Pidgin and creole linguistics. Bloomington: Indiana University Press.

Wurm, S.A.

1978 Reefs-Santa Cruz: Austronesian, but...? In S.A. Wurm and Lois Carrington (eds) Second international conference on Austronesian linguistics: proceedings, pp.969-1010. Pacific Linguistics Series C No. 61. Canberra: Department of Linguistics, Research School of Pacific Studies, The Australian National University.

1982 Papuan languages of Oceania. Tübingen: Gunter Narr.

Wurm, S.A. and Lois Carrington (eds) 
1978 Second international conference on Austronesian linguistics: proceedings. Pacific Linguistics Series C No. 61. Canberra: Department of Linguistics, Research School of Pacific Studies, The Australian National University.

Wurm, S.A. and Shirô Hattori

1981 Language atlas of the Pacific area. Pacific Linguistics Series C No. 66. Canberra: Department of Linguistics, Research School of Pacific Studies, The Australian National University.

Wurm, S.A. (ed.)

1976 New Guinea area languages and language study, vol. 2: Austronesian languages. Pacific Linguistics Series C No. 40. Canberra: Department of Linguistics, Research School of Pacific Studies, The Australian National University.

1977 New Guinea area languages and language study, vol. 3: Language, culture, society and the modern world. Pacific Linguistics Series C No. 40. Canberra: Department of Linguistics, Research School of Pacific Studies, The Australian National University.

Wurm, S.A. and D.C. Laycock

1961-62 The question of language and dialect in New Guinea. Oceania 32:128143.

\section{Notes}

1 The word "language" is here used in the sense that when two people speak their respective mother tongues they do not understand each other (unless one has learnt the other's language). That is, it is not the same as "dialect" or varieties of a language like British English and Australian English. These two terms are confusing because until early this century the word "dialect" was often used to mean what we refer to as "language" today.

2 The claim is based on the following figures.

\begin{tabular}{|c|c|c|c|}
\hline Location & Area (in $\mathrm{km}^{2}$ ) & Number of languages* & Estimated population* \\
\hline Irian Jaya & 400,000 (approx) & $700-750 \dagger$ & $3,000,000$ \\
\hline Papua New Guinea & 476,500 & & $3,000,000$ \\
\hline Solomon Islands & 29,000 & 120 & 200,000 \\
\hline Vanuatu & 14,763 & 200 & 100,000 \\
\hline New Caledonia & 19,103 & 27 & 135,000 \\
\hline Fiji & 18,200 & 2 & 600,000 \\
\hline Total & 957,566 & 1049-1099 & $7,035,000$ \\
\hline
\end{tabular}


5 This is not a necessary result, however. As will be pointed out later some scholars have emphasized the isolation of Melanesians in attempting to explain the diversity of languages found in this part of the world.

6 This is a large topic and readers are referred to Dorian (ed.) (1989) and references therein for further details.

7 There is an extensive and growing literature on contact linguistics. See Thomason and Kaufman (ed.) (1988), for example, and references therein for further reading.

8 This is quite an involved topic and the best I can do is direct readers to Trudgill (1986), for example, for further reading.

${ }^{9}$ See Guy (1990) for a survey of the relationship between social conditions of change and their linguistic outcomes and Ross (1991) for a refinement on Guy's treatment.

10 Trading does not always produce new languages. Instances of "silent" trading between different linguistic groups have been reported in Papua New Guinea for example (e.g. Harding 1967:64). In these trading sessions goods were exchanged but no language was spoken.

11 There is again a vast and ever growing literature on pidgins and pidginization and the reader is directed to Holm (1988), Mühlhäusler (1986), and Valdman (ed.) (1977) and references therein for further details. Pidgin languages are said to become creolized (or to become creole languages) when they are spoken natively by a population although linguists do not yet agree about what the distinguishing features of creoles are.

12 For some other examples see Geraghty (1994), Lynch (1994), Bugenhagen (1994), Tryon (1994) and Ross (1994).

13 Clark (1986:341) notes that it may also be the case that the Pn languages borrowed culturally as well but that such borrowings may have been swamped by intimate borrowing.

14 See for example Capell $(1962,1971)$.

15 These include Lusi (Thurston 1982, 1987, 1994) (although Thurston prefers to use the term pidginization to describe this case), Magori (Dutton 1976), Maisin (Lynch 1977; Ross 1984) and Reefs-Santa Cruz (Lincoln 1978; Wurm 1978).

16 Thurston's use of the word "pidginization" is not the normal one. For example, the resulting or affected language does not cease to be someone's native language.

17 The two which have not been documented are one reported by Jones (1985) and one reported by Harding $(1967: 6,203)$. The former was a Mekeo-based pidgin similar to two others reported in the same place. However, as it had fallen into desuetude at the time of recording nothing more is known about it. The second pidgin is said to have been a pidgin form of the Siassi language. At one time Hees' so-called "Tolai-Nakanai" trade language was also thought to be a pidgin (Dutton 1978:352, fn. 12). However, closer examination shows that it was most probably not a pidgin but was basically Minigir with a little Meramera/Nakanai mixed in (Dutton and Ross 1992).

18 This is in contrast to a number that have been reported arising out of NAn-NAn contact (Foley 1986:30-31).

19 See Grace $(1985,1990)$ for defining features of Ray's and Capell's ideas.

20 Isolation has often been proposed as an explanation for diversity but this is so opposed to the sort of evidence discussed here that it cannot be maintained even as a part explanation. People will cross the apparently most inhibiting terrain to be in contact with others. Also, as Laycock (1982:2) points out, the largest languages are in the most isolated (from our point of view) areas (e.g. the Highlands of Papua New Guinea), whereas the most diverse are in areas of easy terrain where extensive contacts abound. People have been trading, marrying and fighting with each other for aeons. 